\title{
'Beware of hype,' AIDS conference told
}

Vancouver. Leading AIDS scientists warned this week against incautious optimism and excessive hype over early results of new, clinical trials of combination drug treatments for AIDS. Their warning came as the eleventh International Conference on AIDS opened in Canada with a barrage of good news about the war against the disease.

The latest results of several small clinical trials of different combination therapies were due to be released at Vancouver today (11 July), indicating that the therapies are able successfully to repress the viral load of subjects for at least a year.

The trial results will confirm that the expensive and complex drug regimens are able to drive viral load back down below the level detected by blood tests. But there is no evidence that the virus can be eradicated from the body, where it almost certainly remains in the lymph nodes and the central nervous system.

The optimistic mood spurred by these trials among the 15,000 scientists, doctors, activists and journalists who are attending the conference was compounded by Robert Gallo, the veteran AIDS researcher who now directs the Institute of Human Virology in Baltimore, Maryland. Gallo released new evidence of a correlation between levels of chemokines and a natural ability to resist HIV. He predicted that treatment with chemokines or other 'biological' inhibitors would ultimately provide a way of safely controlling HIV.

The United Nations programme on AIDS (UNAIDS) also reported that two of the developing countries hit earliest and hardest by the pandemic - Thailand and Uganda - have successfully reduced the rate of HIV infection, suggesting that health and education programmes are working, even in the most adverse circumstances.

But the domination of the conference by soaring expectations for the combination therapies - which normally put patients on three drugs, including protease inhibitors and the newer reverse transcriptase inhibitors - led officials repeatedly to stress the limitations of such therapies.

"We are at a crossroads in the history of the pandemic," said Martin Schechter, an AIDS researcher at the University of British Columbia and conference co-chair. "We are beginning to see glimmers of hope - but we must stress that they are only glimmers." Peter Piot, director of UNAIDS, warned that the combination therapies may raise unrealizable expectations: "Let's not allow the pendulum to swing from pessimism to hype and excessive optimism."

William Paul, the director of the Office of AIDS Research at the US National Institutes of Health, who directs AIDS research programmes worth $\$ 1.4$ billion, warned of a "dreadful duality" if the industrialized nations pursue costly and sophisticated drug therapies at the expense of approaches that might benefit the poor countries, where 90 per cent of new HIV infections now arise. Paul and others called for renewed efforts to find a protective vaccine to prevent HIV infection (see below).

Results from various small combination therapy trials due to be released at Vancouver this week confirm that the drugs are as successful in suppressing viral load after a year as they had been after six months. In most cases, patients who began therapy shortly after being infected by HIV develop no physical symptoms, and have their viral load reduced to levels undetectable in the blood stream. The trials also uncovered few significant side-effects.

But the therapies cost $\$ 20,000$ or so, and as Piot pointed out, even if that fell to $\$ 5,000$ it would still cost $\$ 100$ billion a year to treat the 20 million infected individuals on the planet. Critics maintain that any deviation from the strict regimens used in the current small, closely monitored trials may foster resistance to the therapy. Concern also surrounds the unknown effects of the toxicity introduced to the body through indefinite treatment with these combinations.

Gallo, meanwhile, reported that unpublished data from a study of haemophiliacs by an Italian team led by Daniel Zagury, and from a British study of homosexual men, both show strong correlations between the level of C-chemokines in the body and its resistance to HIV in the face of direct exposure. He told a packed hall, with many hundreds locked outside, that this and other biological therapies could be cheaper and far less toxic than the chemical inhibitors now being used in combination therapy.

Attempts to control the expansion of AIDS in the developing world by changing public behaviour were bolstered by news from Uganda, where HIV prevalence among pregnant women had fallen from 21 per cent in 1990-93 to 15 per cent in 1994-95. In Thailand, prevalence among male army conscripts has fallen from a peak of 3.7 per cent to 2.4 per cent last year, and is still falling, according to Damrong Boonyoen, director of the Thai Department of Communicable Disease Control.

Drug companies kept a high profile throughout the conference, shipping in doctors from all over the world and running major symposia next to the main programme. Apart from a few noisy protests, most AIDS activists at the conference appeared to welcome the renewed interest of the pharmaceutical companies - in sharp contrast to the mutual fear and loathing expressed at some previous AIDS meetings.

Colin Macilwain

\section{Double push for new vaccine candidates}

THE growing realization that AIDS vaccine development work has virtually ground to a halt (see Nature 378, 323; 1995) led to two major initiatives being announced at the International Conference on AIDS this week, each aimed at kick-starting an effective programme.

William Paul, director of the Office of AIDS Research (OAR) at the US National Institutes of Health (NIH), promised to "increase resources for research on vaccines" and to launch what he called a "restructured, redirected vaccine research programme" at $\mathrm{NIH}$.

Meanwhile, a newly established International AIDS Vaccine Initiative (IAVA), backed by start-up funds from the Rockefeller Foundation and other charities, pledged to raise $\$ 50$ million over the next three years to help to prepare vaccines for use in poor countries.

Paul said that he would fully implement the recommendations of the vaccine component of a recent comprehensive review of the AIDS research programme, which calls for a larger, fully integrated vaccine research programme led by "a distinguished non-governmental scientist".
But Seth Berkley of Rockefeller Foundation, who chairs IAVA, said that the current low level of NIH support for vaccine development is "scandalous". Although NIH spends 8 per cent of its AIDS budget - around $\$ 100$ million a year - on vaccine work, only about $\$ 5$ million is being spent worldwide on preparing new candidate vaccines, Berkley says. Industry has stopped supporting such work because of diminishing prospects of large-scale vaccine trials in the United States, he adds, and the NIH has not filled the gap.

IAVA has $\$ 5$ million for its first year, but hopes to raise between $\$ 8$ and $\$ 12$ million next year, and $\$ 20$ to $\$ 30$ million the year after that, says Berkley. Peggy Johnston, IAVA's scientific director, says that some of money might come from the World Bank.

Johnston, who was deputy director of the Division of AIDS at the National Institute of Allergy and Infectious Diseases (NIAID) before joining IAVA this year, says that $\mathrm{NIH}$ has been relying on industry to come up with potential vaccines, and that "a critical gap" has developed, which IAVA can help to fill.

c. $\mathbf{M}$ 